Volume 2

Number 2 Teaching Secrecy

January 2021

\title{
Questions of Professional Practice and Reporting on State Secrets: Glenn Greenwald and the NSA Leaks
}

Rebecca M. Rice

University of Nevada Las Vegas, rebecca.rice-1@colorado.edu

Follow this and additional works at: https://scholarworks.sjsu.edu/secrecyandsociety

Part of the American Politics Commons, Journalism Studies Commons, and the Speech and Rhetorical Studies Commons

\section{Recommended Citation}

Rice, Rebecca M.. 2021. "Questions of Professional Practice and Reporting on State Secrets: Glenn Greenwald and the NSA Leaks." Secrecy and Society 2(2). https://doi.org/ 10.31979/2377-6188.2021.020207 https://scholarworks.sjsu.edu/secrecyandsociety/vol2/ iss $2 / 7$

This Article is brought to you for free and open access by the School of Information at SJSU ScholarWorks. It has been accepted for inclusion in Secrecy and Society by an authorized administrator of SJSU ScholarWorks. For more information, please contact scholarworks@sjsu.edu. 


\title{
Questions of Professional Practice and Reporting on State Secrets: Glenn Greenwald and the NSA Leaks
}

\author{
Abstract \\ In 2013, journalist Glenn Greenwald met with Edward Snowden, who leaked the most \\ documents in the history of the U.S. National Security Agency (NSA). Greenwald reported \\ on these documents and proved that the NSA spied on millions of American citizens. \\ However, he also provided commentary about the state of journalism and argued that \\ journalists are often complicit in the keeping of state secrets. Using a rhetorical analysis of \\ Greenwald's writings in The Guardian and his later book, this essay argues that journalists \\ function as a technical audience that debates professional standards for leaking secrets. In \\ Greenwald's case, journalists were involved in the "re-secreting" of NSA behavior as they \\ focused their coverage on Greenwald. This essay finds that secrets are communicatively \\ revealed and concealed using different rhetorical appeals. In an age of political hostility \\ toward journalists, the success of leak journalism in starting public discussion has \\ significance for democratic deliberation.
}

\section{Keywords}

journalism, leaks, national security, Glenn Greenwald, National Security Agency, secrecy, Edward Snowden, state secrets, surveillance

\section{Cover Page Footnote}

Rebecca Rice is an assistant professor in the Department of Communication at University of Nevada Las Vegas. She wishes to thank Bryan Taylor, Sara Hayden, and Megan Cullinan for their help in developing this essay. Correspondence can be directed to:

rebecca.rice@unlv.edu. 


\title{
Questions of Professional Practice and Reporting on State Secrets: Glenn Greenwald and the NSA Leaks
}

\author{
Rebecca M. Rice
}

\begin{abstract}
In 2013, journalist Glenn Greenwald met with Edward Snowden, who leaked the most documents in the history of the U.S. National Security Agency (NSA). Greenwald reported on these documents and proved that the NSA spied on millions of American citizens. However, Greenwald also provided commentary about the state of journalism and argued that journalists are often complicit in the keeping of state secrets. Using a rhetorical analysis of Greenwald's writings in The Guardian and his later book, this essay argues that journalists function as a technical audience that debates professional standards for leaking secrets. In Greenwald's case, journalists were involved in the "re-secreting" of NSA behavior as they focused their coverage on Greenwald. This essay finds that secrets are communicatively revealed and concealed using different rhetorical appeals. In an age of political hostility toward journalists, the success of leak journalism in starting public discussion has significance for democratic deliberation.
\end{abstract}

Keywords: Glenn Greenwald, journalism, leaks, national security, National Security Agency, secrecy, Edward Snowden, state secrets, surveillance

Journalistic practice is currently a question of public and political significance: US President Donald Trump expressed open animosity toward the media and disputed many instances of reporting as "fake news" (Carlson 2018). The tension between journalists and the U.S. government is not new, however, and has repeatedly occurred when journalists uncover and report on information the state would prefer remains secret. The 2013 National Security Agency (NSA) leaks were a flashpoint for this tension. Edward 
Snowden, a former government contractor, leaked documents that revealed that the NSA was collecting metadata on millions of Americans without a court warrant. Glenn Greenwald, a journalist for The Guardian, reported on these leaks and later wrote No Place to Hide about his experience. In the process of his reporting, Greenwald found himself in the crossfire - both from U.S. politicians and fellow journalists - and was even labeled a traitor for exposing state secrets. 
The Greenwald case demonstrates that in addition to governmental condemnation of leak reporting, journalists must also engage in conversations about the ethics of reporting on state secrets. In his writings, Greenwald spent time critiquing fellow journalists for failing to do more to disclose state abuses. In return, some journalists labeled Greenwald a "blogger" or "advocate" and condemned his stance as too adversarial (e.g., Cohen and Kaufman 2013). The Greenwald example is a compelling case where professional standards and public right-to-know clash in journalistic coverage of leaked documents. This analysis demonstrates that alongside politicians, journalists can also be complicit in the burying of state secrets through their choices in reporting coverage.

This case demonstrates the complicated politics of reporting on national security secrets as fellow reporters began debating the ethics of Greenwald's disclosures. By asking if Greenwald conformed to professional standards, journalists shifted focus away from the content of the NSA leaks, and instead to a discussion of journalistic practice. Political opponents of the leaks co-opted this discussion through a process that Cloud (2014) calls "resecreting," or directing attention away from state secrets and instead toward the source of the leaks. This essay finds that in the public arena, appeals to a technical audience (in this case, journalists) can silence discussions of leaked information. Thus, the role journalists play in reporting on leaks must be examined for its effects on public deliberation of state secrets. In the 
2020 US political climate, it is easy to point to government animosity toward journalists as a strategy to sow mistrust and eliminate dissenting opinions (Carlson 2018); however, the media also plays a role in re-secreting leaked information. Increased understanding of this role can shed light on processes of uncovering and recovering secrets through communication, and the effects on public deliberation.

This essay argues that the case of the NSA leaks complicates views of journalists and their duties to report (or not) on state secrets. Journalists do not solely provide information for public deliberation; they also interpret information based on their professional standards and shared history. Using Goodnight's idea of technical and public spheres of argument, I examine the consequences of journalists' duties to both, especially concerning reporting on national security issues. This essay makes two primary contributions. First, it contributes to secrecy studies by demonstrating how secrets are communicatively constructed and move along the continuum of concealment and revelation. Using Goodnight's spheres of argument demonstrates that the segmentation of audiences and appeals can rhetorically maintain secrecy. Second, the essay finds that technical communities may contain secrets through their enforcement of norms of professionalism. Journalists, in particular, may appear to be primarily revealers of secrets, but can also conceal secrets through their construction of boundaries of their profession. I first review literature about the public sphere, state secrets, and the role of 
journalists. Next, I employ rhetorical analysis to analyze Greenwald's articles and book about the NSA. I consider the implications of Greenwald's reports as a lightning rod for public discussion and journalistic discussion of ethics of revelation of secrets.

\section{Literature Review: Journalists, Secrecy, and Leak Reporting}

The history of journalism demonstrates that this is a career field that has sought to professionalize and create ethical standards over time. Journalists incorporated "objectivity" and the representation of the public interest into their definition of the profession in the early 20th century. Linking these two values together, they legitimated their claim to Constitutional rights of the American people by becoming a "voice" for the people (Schiller 1979, 47). Journalists took on the role of professionals who were qualified to determine the public's interests and needs. They claimed to represent these interests using impartial, scientific methods to justify this claim (Tuchman 1978, 107). Along with this emphasis on neutrality have come demands to behave "prefossionally" as a journalist (Zelizer 1993, 220). These moves toward professionalization drew boundaries around journalism and the behavior that journalists should engage in, most notably, that journalists should remain neutral toward their subjects.

However, in their choices about what to report, journalists can never fully remain neutral. Zelizer (1993) extends this discussion by labeling 
journalists as an "interpretive community" that co-constructs interpretations of events (219) by both eye witnessing events as they unfold, and judging the significance of events historically. An interpretive community is united by shared interpretations of reality, particularly of public events. Professional renegotiation occurs around events that do not fit with stories of appropriate practice, and in this way, that discourse then provides a guide for day-today journalism (Zelizer 1993, 233).

The struggle over journalists' commitment to objectivity and public advocacy has become an area of renewed conflict since 9/11. Greenwald's strategy for dealing with leaks demonstrates contested professional ground about a journalist's duty when reporting on national security: are the media obligated to report on national security abuses, or should they comply with government requests for secrecy? This context is essential to understanding Greenwald's reporting as a member of the journalistic interpretive community.

Schudson (2002) labels $9 / 11$ as a moment when the press shifted from their standard reporting on controversy to one of consensus, in which the nation entered a time of mourning and criticism of the government was inappropriate. The press aligned itself with the American people, leading to a tone of patriotic solidarity, which allowed the press and public to bear witness and mourn the national tragedy together (Carey 2002; Rosen 2002; Zelizer 2002). The reporting immediately after $9 / 11$ showed the ugly side of 
nationalistic fervor (Carey 2002, 71), and professional journalists and scholars later called for a return to critical, balanced reporting of the news (Schudson 2002, 37).

The press considers itself specially qualified to report on issues of national security to the public; however, scholars have also criticized media reporting as too simplistic to create meaningful debate (Aubin 1998;

Frievogel 2009; Papandrea 2008). Due to concerns about national security, and the media's unique position in reporting this information to the public, the mainstream press is not always welcoming of leaks. Before Edward Snowden, the treatment of two sources of state secrets represented the media's mood post-9/11: WikiLeaks and Chelsea Manning. Hindman and Thomas (2014) studied the mainstream media's framing of WikiLeaks, a website that publishes classified information, concluding that the "old" media (i.e., print outlets) engaged in criticism of WikiLeaks for not showing proper maturity toward news stories. Traditional media outlets disliked WikiLeak's methods of disclosure, which often includes "data dumps," or posting numerous documents to the web with no commentary (Hindmann and Thomas 2014,546$)$. In response to these leaks, the media responded by drawing boundaries, claiming that dumped data did not qualify as journalism.

In addition to condemnation of WikiLeaks, one source who chose to work with the website, Chelsea Manning, faced difficult press coverage. 
Manning is a transgender woman, and many stories about her focused on her gender identity instead of the substance of her leaked documents, which included a controversial video of US troops firing on Iraqi civilians and laughing (Cloud 2014). Cloud (2014) argues that Manning failed to start a public conversation about security because of the "re-secreting" of her story by the press (81). Coverage of Manning often focused on her gender identity and characterized her as confused and lonely. US politicians seized on these characterizations as a way to invalidate her concerns about the US military. In addition to drawing lines around professional behavior, journalists muddled stories of these leaks by focusing on the source instead of the secrets revealed.

The Snowden leaks differ from these past cases because Greenwald did not "dump" Snowden's documents, and instead reported on documents of his choosing. In this way, he fulfilled more of a traditional journalistic role. Chadwick and Collister (2014) call this a case of "boundary-drawing," which allowed The Guardian to stay in the center of the NSA story using old and new media tactics (2423). These tactics indicate a commitment to professional codes of conduct by bringing in an expert to report on the leaks and positioning Snowden as a source. Journalistic involvement in leaks has continued, for example, in the case of Daphne Caruana Galizia, who spearheaded reporting on the Panama Papers, a trove of documents from offshore law firm Mossack Fonseca that demonstrated widespread use of tax 
havens by financial and political elites worldwide. As Lynch and Levine (2016) point out, what makes these leaks significant is the revelation of legal, rather than illegal, practices, which invited discussion of the rupture between laws and the will of the public. Lynch and Levine (2016) encourage scholars to ask questions about leaked documents, including how the public interacts with these leaks, if leaks can be used to encourage accountability, and how journalists can create a code of ethics around leaks. Since the Snowden leaks, scholars have demonstrated that leaks from political officials have garnered more attention than leaks from citizens (Sampedro et al. 2018) and that journalists continue to come under fire for their role in leak reporting (Vanacker 2016). Thus, the struggle of leaking state secrets is not simply about the content of the leaks, but also the context and key players in the disclosures.

Secrecy studies directs attention toward the nature of government leaks as worthy of study. Secrets exist along a continuum - secrets are not static; instead, they are revealed and concealed in practice (Birchall 2016). Maret (2016) labels secrets as a wicked, or entrenched, societal problem, and points to examples of power abuses that have remained secret. Secrets, however, are often justified through rational and legal provisions - Maret (2016) here lists security classifications, business protections, and legal rights. Leaked documents are worthy of study because of their travel along the secrecy continuum. 
At the moment of the leak, leaked state secrets move dramatically toward the "revealed" end of the spectrum; however, they also require interpretation, circulation, and understanding to stay revealed. Further, leaks are often the product of moral or ethical objections on the part of the leaker, whether the leaked information is legally protected or not. Finally, in the act of leaking, secrets compound - the data is now revealed, but the identity of the source may also be exposed. In discussions of leaked documents, the source or sources of the leak are also subject to public scrutiny.

As studies by Lynch and Levine (2016) and Maret (2016) note, secrets are often concealed by field protections, whether that be government classification systems or the legal system. Secrets, rather than being instantly inflammatory, are often profoundly bureaucratic and may appear mundane (Jansen, 2016). The pull between revealed and concealed, then, is also a pull between public and private, the field of practitioners and outsiders. Journalistic reporting on leaks and discussion of leaks demonstrates a clash of different professional and ethical standards (Johnson et al. 2020). Greenwald's case poses interesting questions about the professional community around leaked state secrets, demonstrating that journalists' engagement in debate around their profession can also cast interest away from the content of the secrets revealed. One rhetorical tool that can be used to analyze this struggle is spheres of argument - discussed 
next.

\section{Public and Technical Argumentation}

Argumentation scholars have considered how argumentative choices and appeals can exclude the general public from understanding - a rhetorical move that, in effect, makes some topics secret. Habermas (1974/1964) reignited interest in the public sphere by defining this as an arena where citizens debate issues of common concern, creating a check on state apparatuses. G. Thomas Goodnight posits three spheres on which arguments are built and to which rhetors can appeal. Goodnight (1982) proposes that there are additional spheres of arguments and that in these spheres, differing appeals are acceptable, which limits who can participate. The first appeal is to the private sphere, and is invoked through informal identification with another person. The second is an appeal to partisanship, or the public sphere. The final is an appeal to specialized occupations or knowledge, or the technical sphere (Goodnight 1982, 218). Each sphere requires different grounds and has different communicative norms, and arguments in one sphere table concerns of other spheres, which are no longer "in play" (Goodnight 2012, 260). In the public sphere, Goodnight (2012) stresses the function of public deliberation, which occurs as the public tries to resolve uncertainty by sharing in a hypothetical construction of the future. Conversely, in the technical sphere, argumentative norms are 
guided by specialized interests, primarily work in an occupation, which limits the subject matter of deliberation (Goodnight 1982). Technical sphere deliberation focuses on questions of practice within the profession (Goodnight 2012) and questions of knowledge that are observable and measurable (Farrell 1976).

The public and technical spheres may be at odds, as the technical sphere withholds specialized arguments from public discussion. Farrell and Goodnight (1981) warn that in technical debates, questions of ethics are precluded in favor of focus on technical capability. Scholars have focused on the debate of technical issues within scientific communities (Sovacool 2009), nuclear power plant operations (Farrell and Goodnight 1981), and legal communities (Schiappa 2012). The expert culture around national security similarly excludes the public from deliberation. For example, Schiappa $(1982,253)$ finds that "nukespeak" during the Cold War sanitized language surrounding nuclear weapons, and used excessive bureaucratization to insulate nuclear information from the public. Once this information was sanitized, questions of morality became obsolete (Schiappa 1982). However, security crises can also become matters of public concern that create openings for public sphere deliberation (Mitchell 2002).

A transition from technical to public sphere appeals can also occur when experts disagree and take to public forums to fight for resources, leadership, and control (Goodnight 1982). If the governing forums of the 
discipline fail to satisfy them, they may appeal to the public. The arguments must then be made congruent with public deliberation practices. In the public sphere, speakers will use "common language, values, and reasoning so that the disagreement [can] be settled to the satisfaction of all those concerned" (Goodnight 2012, 202). Goodnight's (2012) interest in how the grounds of arguments change is especially relevant to this research and can illuminate how secrets move from a concealed state in spheres of professional practice to a revealed state in the public sphere.

Despite journalists' professional disagreements, public sphere scholarship has placed them as special actors in the public sphere, often acting as public sphere advocates and using specialized skills to provide the public with information. Bitzer (1987) says that the media represents the interests of the public by upholding rigorous professional standards and asking difficult questions to gain access to information otherwise inaccessible to the public. The media concerns itself with the weighing of truths and invites the public to discuss its interests (Bitzer 1987). The media acts on behalf of the public as it participates in public communication. Hauser (1987) also suggests that the press should transmit public sphere information, or "the citizenry can neither conduct intelligent discussions nor form balanced opinions" (439). Goodnight (1982) sees that the media could be a tool for public deliberation, but criticizes it as functioning as a tool of consumption rather than tools to create a shared future. Previous public 
sphere scholarship claims that the media acts within the public sphere to provide the public with tools to deliberate. However, the media also possesses specialized knowledge and professional boundaries, and their practices have been the subject of scholarly criticism. Although journalists do act in the public sphere, Greenwald's writings demonstrate that journalists are also members of a technical community that debates questions of professional standards. This unique duality has the potential to create both openings and closures in the discussion of state secrets. This essay turns to rhetorical analysis of Greenwald's arguments next to understand the consequences of appeals to both spheres of argument.

\section{Greenwald Publishes the NSA Leaks}

In the following sections, I analyze newspaper articles written by Glenn Greenwald, as well as his 2014 book, No Place to Hide: Edward Snowden, The NSA, and The U.S. Surveillance State (NPTH). I first provide a summary of the case and the texts chosen for rhetorical analysis.

In April 2013, journalists Glenn Greenwald, Laura Poitras, and Ewen MacAskill flew to Hong Kong to meet an anonymous source who claimed to have US National Security Agency documents. Their source, 29-year-old NSA contractor Edward Snowden, copied thousands of confidential documents after becoming disillusioned with the NSA's practices. Holed up in a hotel room in Hong Kong, the journalists interviewed Snowden for hours 
as he explained NSA surveillance programs that allowed the agency to collect billions of pieces of information about American citizens. While in Hong Kong, Greenwald began publishing articles about the leaks in The Guardian.

The leaks revealed that the NSA did not merely spy on foreign targets, as was commonly believed, but was also gathering information from Americans' email accounts, online searches, and telephone records without a court warrant (Greenwald, 2014). Greenwald published nine articles about the NSA documents in The Guardian during the summer of 2013. In May of 2014, he published No Place to Hide: Edward Snowden, the NSA, and the U.S. Surveillance State. The book detailed his meeting with Snowden in Hong Kong and his growing concerns about the NSA's actions. Greenwald also discussed his personal biography and interest in the leaks - he was previously a lawyer and ran a blog, "Unclaimed Territory," about post-9/11 civil liberties violations and previously authored a book about the Bush administration and the USA PATRIOT Act before writing for The Guardian. Through these artifacts, I examine how Greenwald demonstrates that state surveillance is a topic worthy of discussion in the public sphere, and therefore should be reported on by more journalists.

\section{Greenwald's Articles in The Guardian}

On Wednesday, June 5th, 2013, Greenwald (2013a) published the 
breaking news in The Guardian: a court order that allowed the NSA to collect American's metadata through Verizon, one of the largest phone service providers in the country. The story was picked up by many other news agencies and shared around the web, going viral overnight. On June 6th, Greenwald reported on PRISM, a program that allowed the NSA to access online data from Apple, Google, Yahoo, and other electronic communication providers (Greenwald 2013b). The revelations continued with a new article published every few days, each from a top-secret NSA file. On June 9th, Greenwald revealed Edward Snowden's identity as the source of this leaked information, writing an article that included an interview filmed by Laura Poitras. Greenwald gave Snowden's background, told the story of how he obtained NSA documents and reiterated why these findings were significant (Greenwald 2013c). The articles continued, amounting to nine in all by the end of July. The news of NSA surveillance was picked up by almost every news network, but Greenwald was the first to deliver the scoop and provided all of the information reported by other channels. ${ }^{1}$

\section{No Place to Hide: Edward Snowden, The NSA, and The US Surveillance State}

In NPTH, Greenwald talks about his meeting with Edward Snowden and the documents Snowden gave him. The book tells the story of how

1 As Greenwald engaged in a back-and-forth debate with The Guardian's lawyers about publication of his article about PRISM, The Washington Post published a piece using the PRISM documents, thus "scooping" the story out from under The Guardian. However, all other NSA findings were initially reported by Greenwald and MacAskill in The Guardian (Greenwald 2014). 
Greenwald obtained the documents, and the time leading up to his first Guardian publication. In this book, Greenwald focuses explicitly on surveillance, narrowing his purpose from post-9/11 security concerns, which he has published about in the past, to the NSA.

Greenwald first discusses his meeting with Snowden. Though Snowden attempted to reach Greenwald months earlier, it was not until Laura Poitras, a documentary filmmaker, invited Greenwald to cover a story on the NSA that the two communicated. Greenwald tells the story of his trip to Hong Kong to meet Snowden and report on his documents. Next, Greenwald includes a section of documents leaked from the NSA and uses the NSA's slides to show that their philosophy is to "collect it all," or as much information about US citizens and foreign targets as possible. He then discusses the repercussions of surveillance, including a loss of individualism. and explains that "What makes a surveillance system effective in controlling human behavior is the knowledge that one's words and actions are susceptible to monitoring" (Greenwald 2014, 175). Finally, Greenwald says that the mainstream media has been complicit in these abuses, and by refusing to report on them, they fail to perform a crucial check on the government. NPTH was well received by critics and became a New York Times bestseller. Greenwald takes issue with both the secret government surveillance community and with journalists for being complicit in state surveillance abuses by not reporting on them. I analyze Greenwald's two 
veins of criticism in the following section.

\section{Analysis: Questioning Public and Professional Practices through the NSA Leaks}

Greenwald's writings on the NSA leaks can be seen as both public and technical sphere arguments. First, he appeals to the public to discuss the leaks, but he next turns to his own technical community to debate journalistic practices surrounding state secrets. This debate demonstrates the duality of professional commitments that journalists consider when reporting on leaked documents. Greenwald's arguments play up the public sphere role of journalists, which, for him, includes a move away from the professional standard of "objectivity" and toward advocacy for the public. Here I analyze the dual appeals of Greenwald's arguments to reveal the NSA leaks to the public sphere and debate journalistic professional norms around secrecy.

\section{Moving the NSA Leaks to the Public Sphere}

First, Greenwald tries to argue that the public should discuss these leaks. Greenwald characterizes the NSA as an organization without public oversight, for example, by citing documents that ask NSA analysts to "use their judgment" to determine whether to pull metadata, rather than asking for a FISA court warrant (Greenwald 2013e). The NSA has discretion over who to target and what information to collect, demonstrating their concern with technical practices rather than ethical concerns surrounding these 
practices. Greenwald explains that "the vast amount of discretion vested in NSA analysts is also demonstrated by the training and briefings given to them by the agency" $(2013 d, 8)$. Greenwald's descriptions of the NSA closely parallel Goodnight's $(2012,260)$ technical sphere of argument, in which "technical arguments are stamped with procedure and rule where state of the art practice is always at issue." The NSA has discretion over who to target and what information to collect, demonstrating their concern with technical practice rather than ethical appeals consistent with the public sphere.

After characterizing the NSA as isolated and interested only in the capability to conduct surveillance, Greenwald moves discussion about the NSA toward publicly grounded arguments in several ways. He works to deconstruct NSA jargon so the public can understand the documents. For example, Greenwald explains technical terms, like metadata, and potential uses to explain the effects of the surveillance and gives this example in NPTH:

Listening in on a woman calling an abortion clinic might reveal nothing more than someone confirming an appointment with a genericsounding establishment...But the metadata would show far more than that: it would reveal the identity of those who were called. The same is true of calls to a dating service, a gay and lesbian center, a drug addiction clinic, an HIV specialist, or a suicide hotline. (Greenwald 2014, 133)

Greenwald argues that surveillance is invasive by defining terms, explaining NSA programs, and providing common examples to the public. 
Additionally, Greenwald encourages his readers to consider the NSA a shared problem and works dissuade them of the idea that if they have nothing to hide, they have nothing to fear. Greenwald instead argues that "the perception that invasive surveillance is confined only to a marginalized and deserving group of those 'doing wrong' - the bad people - ensures that the majority acquiesces to the abuse of power and even cheers it on" (2014, 182). However, Greenwald says, the government watches many people for reasons beyond terrorist threats or illegal activity. He gives examples from history, saying that Martin Luther King Jr., the civil rights movement, and environmentalists have all been placed under government surveillance. Greenwald says that in the government's eyes, these people were doing something wrong; they were engaging in "political activity that threatened the prevailing order" $(2014,183)$. Greenwald frames the NSA's surveillance as unpatriotic and a threat to US democracy. In addition to explaining how the NSA spies on people, he also explains why the revelation of this secret should concern every US citizen.

However, some journalists condemned Greenwald's choice to reveal secret information. This condemnation led to a separate debate aimed at the journalistic profession, which, I argue, fits with Goodnight's technical sphere.

\section{Debating Journalistic Practices and Ethics}

Greenwald also tries to prove his professional legitimacy and takes issue with current journalistic practices, particularly in his commentary in 
NPTH. Greenwald argues that journalistic culture should be revised to allow for more advocacy, especially to fight government abuses of power. Greenwald $(2014,55)$ says that the current culture of US journalism is inadequate because it "mandates that reporters avoid any clear or declarative statements and incorporate government assertions into their reporting, treating them with respect no matter how frivolous they are." $\mathrm{He}$ says that "especially since 9/11 (though before that as well), the U.S. media in general had been jingoistic and intensely loyal to the government and thus hostile, sometimes viciously so, to anyone who exposed its secrets" (Greenwald 2014, 79). In Greenwald's view, the press has been too sympathetic to the technical sphere of surveillance and has protected this insulated community, which does not serve the interests of the public.

Greenwald's proposed solution to this problem is less objectivity and more advocacy on the part of journalists. He attacks the idea that journalists need to be objective, saying that all news articles serve interests, and "the relevant distinction is not between journalists who have opinions and those who have none, a category that does not exist. It is between journalists who candidly reveal their opinions and those who conceal them, pretending they have none" (Greenwald 2014, 231). Greenwald's arguments are aimed at his own professional community and debate the practices and values of the profession. Greenwald begins this debate by disagreeing with the tactics of fellow journalists and airing these disagreements publicly. He takes issue 
Secrecy and Society, Vol. 2, No. 2 [2021], Art. 7

with professional practices and codes that have been in place for journalists, including the idea of "objectivity," while also calling for more public advocacy.

Greenwald also shares his interpretation of his NSA reporting and argues that his choices align with standards for the profession. Greenwald (2014) makes a historical assessment of the NSA leaks by framing them as a crucial moment of public deliberation when he writes:

Will the digital age usher in the individual liberation and political freedoms that the Internet is uniquely capable of unleashing? Or will it bring about a system of omnipresent monitoring and control, beyond the dreams of even the greatest tyrants of the past? Right now, either path is possible. Our actions will determine where we end up. (6)

Greenwald speculates about the significance of this reporting over time while emphasizing his legitimacy as an eyewitness throughout NPTH, demonstrating his interpretation that the NSA leaks were good journalistic practice.

However, Greenwald's reporting was not always praised by fellow journalists, who wrote in ways that aligned and distanced themselves from him. Greenwald (2014) demonstrates his concern with this when he discusses the implications of being labeled a "blogger" or "advocate" by other news outlets. According to Greenwald (2014), "the media in full then got into a debate about whether I was in fact a 'journalist' as opposed to something else. The most commonly offered alternative was 'activist'" (212). He says that "the designation had real significance on several levels. For 
one, removing the label of 'journalist' diminishes the legitimacy of the reporting. Moreover, turning me into an 'activist' could have legal - that is, criminal - consequences" (Greenwald 2014, 212-213). For example, Sullivan (2013) described Greenwald as "a journalist and lawyer known for objecting to the excesses of government surveillance after $9 / 11$ and for championing civil liberties," and says that as a result, her newspaper, The New York Times, "found itself playing catch-up to this crusading columnist" (Sullivan 2013). These labels served to de-professionalize Greenwald (he is a blogger), or discredit him through bias (he's a lawyer, an advocate, and an activist). In contrast to the norms of professional journalism, which include balanced, neutral content and withholding personal opinions from reporting, Greenwald was labeled as excessively opinionated. He discusses the significance of these labels by pointing to their use in government persecution of leaks. ${ }^{2}$

In the following section, I discuss the impact of Greenwald's arguments on national security journalism and ask how scholars can examine the consequences of journalistic debates about secret information.

\section{Implications: Journalists as Public and Technical Actors}

2 The Department of Justice (DOJ) had recently acquired the Associated Press's telephone records, and in a separate case had prosecuted Fox News journalist James Rosen for not revealing the identity of a source. By labeling Rosen as a co-conspirator to the source, the DOJ was able to compromise his journalistic protection. The DOJ decided, Greenwald $(2014,215)$ says, that "working with one's source to 'steal' classified information was beyond the scope of the 'reporter's job.'" Creating boundaries on what counted as "legitimate reporting," the DOJ was able to prosecute a journalist. 
The Greenwald case has implications for scholarly understandings of processes of revelation and concealment surrounding secrets and the role of journalists in the communicative construction of secrets. On the continuum of concealment and revelation (Birchall 2016), journalists participate in numerous ways to construct the spectrum of secrecy. While journalists may initially appear to be revealers of secrets, their professional condemnation of leak reporting can stifle public deliberation. Greenwald's arguments demonstrate the paradox of professional standards in journalism, between revelation and concealment and objectivity and advocacy, which come to a head in debates about leak reporting. First, this case contributes to secrecy studies by using spheres of argument to analyze appeals made to keep and reveal secrets. One question that secrecy studies can look to answer is how secrets are constructed and maintained through communication. While seemingly contradictory, secrets are constituted by talk as well as lack of talk. Secrecy studies, then, can ask who is allowed to discuss secrets and how they are discussed. Goodnight's (2012) spheres of argument answers this question by analyzing the rhetorical choices and audiences tied to secrets. The public sphere is seemingly the antithesis of secrecy, while the private sphere may appear to be the most secretive.

The technical sphere illuminates different processes of concealmentsecrets that can be hidden in plain sight, masked through language and inaccessible knowledge. The technical sphere can conceal secrets, not just 
by keeping this information from the public, but also by keeping the information from being understandable by the public through the "jargon of evasion" (Jansen 2016, 2). Technical language denies the public access to the conversation (Hauser 1987), and Greenwald demonstrates that one role journalists can take on is the role of translator between technical and public appeals. He does this by choosing which NSA documents to write about and making clear the implications of the materials using plain language and concrete examples. While a common technical sphere retort by the NSA has been that they are not "listening" to Americans' phone calls, Greenwald demonstrates that metadata is as revealing as the content of conversations - a fact that the NSA diminishes. In response to the challenge of public understanding of megaleaks, especially when they require technical knowledge (Lynch and Levine 2016), journalists can play a special role in making this knowledge digestible, applicable, and coherent to the public. Analysis using spheres of argument highlights that communication transforms secrets by transforming both the rhetoric surrounding secrets and their audiences. Greenwald's case is an important example of the communicative process of revelation, and his rhetorical choices contribute directly to the disclosure. Here, moving secrets out of the technical sphere means translating those secrets into something relevant to public understanding. 
However, this case also demonstrates that professional norms can resecret leaked information by directing attention away from the substance of the leaks and toward the practice of leaking information. The legacy of commitment to objectivity in journalism has become an accepted standard that journalists use to defend the boundaries of their profession (Schiller 1979). For Greenwald, this standard is simply a denial of the reality that all writers have opinions and that those opinions come through in what they choose to report on. Greenwald advances a different professional standard that of public accountability and duty - in place of objectivity.

Additionally, Greenwald attempts to create an interpretation of the NSA leaks as historically significant. Re-secreting of leaks can occur, not just through redaction, but through processes of forgetting. Greenwald attempts to advance a historical view where the leaks align with patriotism. This is significant because journalists have cited $9 / 11$ and national security risk as rationales for protection state secrets (Zelizer 2002). Journalistic debate over reporting on leaked documents demonstrates that secrecy of government surveillance an ongoing challenge for journalists as they weigh democratic values and security. As previous studies (e.g., Cloud 2014; Hindmann and Thomas 2014) demonstrate, the media is uncertain about what to do with leaked national security documents and has condemned previous leaks as outside of the scope of journalism. Greenwald instead 
advances the view that reporting on leaked documents is courageous and will stand the test of history.

Coverage of the NSA leaks from other outlets demonstrates that reporters did take up Greenwald's interpretation of the events as significant, and in some cases, affirmed Greenwald's actions as good journalistic practice. For example, Greenwald and other Guardian reports were awarded the 2013 George Polk award in journalism. The award curator explained their decision, saying,

...many of the journalists we have recognised did more than report news. They heightened public awareness with perceptive detection and dogged pursuit of stories that otherwise would not have seen the light of day. Repercussions of the NSA stories in particular will be with us for years to come. (Pengelly 2014)

This commendation judges the NSA stories in a positive light historically and notes journalistic practice as a key component worthy of honor. Responses like this show that some of the journalistic community interpreted Greenwald's actions as correct, and could utilize them as a guide in future national security reporting.

\section{Conclusion}

The aftermath of the NSA leaks demonstrate slight progress and potential for reform, but overall, these changes have been slow. Several bills have died in Congress, including one to defund the NSA altogether (Ackerman 2014). Most dramatically, on June 1st, 2015, key provisions of 
the USA PATRIOT Act (H.R. 3162), including the bulk collection of telephone metadata, expired. The NSA no longer keeps this data, and instead will require telephone companies to keep it, obtaining only information they specifically ask for through a FISA court warrant (Diamond 2015). Recent terrorist attacks by the Islamic State (ISIS) have pushed back on the climate of reporting on national security controversy, however, notably when CNN anchors cast blame on Edward Snowden for weakening surveillance power after the Paris attacks of 2015 (Kopan 2015).

On an individual level, Americans are now slightly more aware of privacy concerns and have taken some steps to control their data online. According to the Pew Research Center, $87 \%$ of Americans surveyed were at least "somewhat aware" of surveillance programs after the Snowden leaks. Of that group, $36 \%$ had taken steps to increase their privacy online (Rainie and Madden 2015). $61 \%$ of those surveyed said that after the NSA leaks, they were not confident that surveillance served the public interest (Rainie and Madden 2015). Snowden's leaks had some impact on the American public, which overall displays less confidence in government surveillance. This data indicates more public sphere awareness and discussion surrounding the NSA, which, before the Snowden leaks, was virtually unknown to most of the American public.

Greenwald's attempt to launch a public discussion about the NSA was a small success, which led to awareness and slight legal reform. The effects 
of his challenge to journalists have yet to be seen; however, I propose that they encourage a different view of journalists, not just as public sphere actors, but a technical sphere with technical interests. Greenwald's rhetoric demonstrates a desire to redraw the boundaries of journalism, which was met with technical sphere pushback. These questions of journalistic practices will rise again with each leak reported by the press. For those studying the secrecy, the journalistic choice to report (or not report) on state secrets impacts not just the professional boundaries of journalism, but the state of public deliberation around this information. As public sphere actors, journalism's internal debates can have significant impacts on the public's opportunity to deliberate about secrets.

\section{References}

Ackerman, Spencer. 2014. "Edward Snowden, a Year on: Reformers Frustrated as NSA Preserves its Power." The Guardian, June 5. https://www.theguardian.com/world/2014/jun/05/edward-snowdenone-year-nsa-surveillance-reform

Aubin, Stephen P. 1998. Distorting Defense: Network News and National Security. Westport, CT: Praeger.

Birchall, Clare. 2016. "Six Answers to the Question 'What Is Secrecy Studies?" Secrecy and Society 1. no.1. http://scholarworks.sjsu.edu/secrecyandsociety/vol1/iss1/2/

Bitzer, Lloyd F. 1987. "Rhetorical Public Communication." Critical Studies in Mass Communication 4, no. 4: 425-428.

Carey, James W. 2002. "American Journalism on, before, and after 
September 11." In Journalism after September 11, edited by Barbie Zelizer and Stuart Allan, 71-90. London: Routledge.

Carlson, Matthew. 2018. "The Information Politics of Journalism in a PostTruth Age." Journalism Studies 19, no. 13: 1879-1888.

Chadwick, Andrew and Simon Collister. 2014. "Boundary-Drawing Power and the Renewal of Professional News Organizations: The Case of The Guardian and the Edward Snowden National Security Agency Leak." International Journal of Communication 8: 2420-2441.

Cloud, Dana. 2014. "Private Manning and the Chamber of Secrets." QED: A Journal of GLBTQ Worldmaking 1, no.1: 80-104.

Cohen, Noam, and Leslie Kaufman. 2013, June 6. "Blogger, with focus on surveillance, is at center of a debate." The New York Times. https://www.nytimes.com/2013/06/07/business/media/antisurveillance-activist-is-at-center-of-new-leak.html

Diamond, Jeremy. 2015. "Patriot Act Provisions have Expired: What Happens Now?" CNN, June 1.

http://www.cnn.com/2015/05/30/politics/what-happens-if-the-patriotact-provisions-expire/index.html

Farrell, Thomas B. 1976. "Knowledge, Consensus, and Rhetorical Theory." Quarterly Journal of Speech 62, no. 1: 1-14.

Farrell, Thomas B., and G. Thomas Goodnight. 1981. "Accidental Rhetoric: The Root Metaphors of Three Mile Island." Communication Monographs 48: $271-300$.

Frievogel, William H. 2009. "Publishing National Security Secrets: The Case for Benign Indeterminancy." Journal of National Security Law and Policy 3, no. 95: 93-119.

Goodnight, G. Thomas. 1982. "Personal, Technical, and Public Spheres of Argument: A Speculative Inquiry into the Art of Public Deliberation." The Journal of the American Forensic Association 18 no. 4: 214-227.

. 1986. "Ronald Reagan's Re-Formulation of the Rhetoric of War: Analysis of the "Zero Option," "Evil Empire," and "Star Wars" Addresses." Quarterly Journal of Speech 72, no. 4: 390-414.

. 2012. "The Personal, Technical, and Public Spheres: A Note on 21st Century Critical Communication Inquiry." Argumentation and Advocacy 48, no. 4: 258-267.

Goodnight, G. Thomas, and Kathryn M. Olson. 2006. "Shared Power, Foreign Policy, and Haiti, 1994: Public Memories of War and Race." Rhetoric and Public Affairs 9. no. 4: 601-634.

Greenwald, Glenn. 2013a. "NSA Collecting Phone Records of Millions of 
Verizon Customers Daily." The Guardian, June 5.

https://www.theguardian.com/world/2013/jun/06/nsa-phone-recordsverizon-court-order

. 2013b. "NSA PRISM Program Taps in to User Data of Apple, Google, and Others." The Guardian, June 6.

https://www.theguardian.com/world/2013/jun/06/us-tech-giants-nsadata

. 2013c. "Edward Snowden: The Whistleblower Behind the NSA

Surveillance Revelations." The Guardian, June 9.

http://www.theguardian.com/world/2013/jun/09/edward-snowden-nsawhistleblower-surveillance

. 2013d. "Boundless Informant: The NSA's Secret Tool to Track Global Surveillance Data." The Guardian, June 11.

http://www.theguardian.com/world/2013/jun/08/nsa-boundlessinformant-global-datamining

. 2013e. "FISA court: A Look Inside a Secret and Empty Process." The Guardian, June 18.

http://www.theguardian.com/commentisfree/2013/jun/19/fisa-courtoversight-process-secrecy

. 2014. No Place to Hide: Edward Snowden, the N.S.A., and the U.S. Surveillance State. New York: Metropolitan Books.

Habermas, Jurgen. 1974/1964. "The Public Sphere: An Encyclopedia Article." Translated by S. Lennox and F. Lennox. New German Critique 3: 49-55.

Hauser, Gerard A. 1987. "Features of the Public Sphere." Critical Studies in Mass Communication 4, no. 4: 437-441.

Hindman, Elizabeth B., and Ryan J. Thomas. 2014. "When Old and New Media Collide: The Case of WikiLeaks." New Media Society 16, no. 4: 541-557.

Jansen, Sue Curry. 2016. "Secrecy, Confidentiality, and 'Dirty Work': The Case of Public Relations." Secrecy and Society 1, no. 1. http://scholarworks.sjsu.edu/secrecyandsociety/vol1/iss1/1/

Johnson, Brett. G., Liz Bent, and Caroline Dade. 2020. "An Ethic of Advocacy: Metajournalistic Discourse on the Practice of Leaks and Whistleblowing from Valerie Plame to the Trump Administration." Journal of Media Ethics 35, no. 1: 2-16. https://doi.org/10.1080/23736992.2020.1731314

Kakutani, Michiko. 2014. "Snowden's Story, Behind the Scenes." The New York Times, May 12. https://www. nytimes.com/2014/05/13/books/noplace-to-hide-by-glenn-greenwald.html 
Kopan, Tal. 2015. November 20). "Political Winds Shifting on Surveillance after Paris Attacks?" CNN, November 20.

http://www.cnn.com/2015/11/20/politics/paris-syria-isis-surveillanceintelligence-politics/

Lynch, Lisa, and David S. Levine. 2016. "Whither Megaleaking? Questions in the Wake of the Panama Papers." Secrecy and Society 1, no.1. http://scholarworks.sjsu.edu/secrecyandsociety/vol1/iss1/7/

Maret, Susan. 2016. "The Charm of Secrecy: Secrecy and Society as Secrecy Studies." Secrecy and Society 1, no 1. http://scholarworks.sjsu.edu/secrecyandsociety/vol1/iss1/1/

McChesney, Robert W. 2002. "September 11 and the Structural Limitations of U.S. Journalism." In Journalism after September 11, edited by Barbie Zelizer and Stuart Allan, 91-100. London: Routledge.

Mitchell, Gordon R. 2002. Public argument-driven security studies. Argumentation and Advocacy 39, no. 1: 57-71.

Papandrea, Mary-Rose. 2008. "Lapdogs, Watchdogs, and Scapegoats: The Press and National Security Information." Indiana Law Journal January (83): 233-305.

Pengelly, Martin. 2014. "Journalists who Broke NSA story in Guardian Receive George Polk Awards." The Guardian, February 16. http://www.theguardian.com/world/2014/feb/16/guardian-nsasnowden-george-polk-awards

Rainie, Lee, and Mary Madden. 2015. "American's Privacy Strategies PostSnowden." Pew Research Center, March 16. http://www.pewinternet.org/2015/03/16/americans-privacy-strategiespost-snowden/

Rosen, Jay. 2002. "September 11 in the Mind of American Journalism." In Journalism after September 11, edited by Barbie Zelizer and Stuart Allan, 27-35. London: Routledge.

Sampedro, Victor, F. Javier López-Ferrández, and Álvaro Carretero. 2018. "Leaks-based journalism and media scandals: From official sources to the networked Fourth Estate?" European Journal of Communication 33: 255-270. https://doi.org/10.1177/0267323118763907

Schiappa, Edward. 1982. "The Rhetoric of Nukespeak." Communication Monographs 56, no. 3: 253-274.

. 2012. "Defining Marriage in California: An Analysis of Public and Technical Argument." Argumentation and Advocacy 48: 216-230.

Schiller, Dan. 1979. "An Historical Approach to Objectivity and Professionalism in American News Reporting." Journal of 
Communication 29, no.4: 46-57.

Schudson, Michael. 2002. "What's Unusual about Covering Politics as Usual." In Journalism after September 11, edited by Barbie Zelizer and Stuart Allan, 36-47. London: Routledge.

Sovacool, Benjamin K. 2009. "Spheres of Argument Concerning Oil Exploration in the Arctic National Wildlife Refuge: A Crisis of Environmental Rhetoric?" Environmental Communication 2, no. 3: 340361.

Sullivan, Margaret. 2013. "Sources with Secrets Find New Outlets for Sharing." The New York Times. June 15. https://www.nytimes.com/2013/06/16/public-editor/sources-withsecrets-find-new-outlets-for-sharing.html

Tuchman, Gaye. 1978. "Professionalism as an Agent of Legitimation." Journal of Communication 28, no. 2:106-113.

Ulin, David L. 2014. "'No Place to Hide' a Vital Discussion on Snowden's Revelations." The Los Angeles Times, May 13.

http://www.latimes.com/books/jacketcopy/la-et-jc-glenn-greenwald20140513-story.html - page $=1$

Vanacker, Bastiaan. 2016. "Just Doing His Job: Journalism Defending its Turf in a Time of Leak Investigations." Journalism Studies 17: 573589. https://doi.org/10.1080/1461670X.2014.996030

Zelizer, Barbie. 1993. "Journalists as Interpretive Communities." Critical Studies in Mass Communication 10, no. 3: 219-237. . 2002. Photography, Journalism, and Trauma. In Journalism after September 11, edited by Barbie Zelizer and Stuart Allan, 48-68. London: Routledge. 